\title{
Effect of the combined isotonic technique for proprioceptive neuromuscular facilitation and taping on pain and grip strength in patients with lateral epicondylitis: a randomized clinical trial
}

\author{
Beom-Ryong Kim ${ }^{1,2}$, Dong-Hyun Yi' ${ }^{2}$ Jong-Eun Yim ${ }^{2 * *}$ \\ 'Department of Physical Therapy, Design Hospital, Jeonju, Korea \\ ${ }^{2}$ Department of Physical Therapy, Graduate School of Sahmyook University, Seoul, Korea
}

The purpose of this study was to investigate the effect of the combined isotonic technique (CIT) for proprioceptive neuromuscular facilitation and taping intervention on pain and grip strength in patients with lateral epicondylitis (LE). Twenty subjects with LE were treated 5 times a week for 4 weeks. Patients were randomized to an experimental group $(n=10)$ with taping after CIT and a control group $(n=10)$ with taping after stretching. A visual analogue scale (VAS) was used to measure changes in pain. $A$ hand dynamometer was used to measure grip strength. $A$ paired $t$-test was performed to compare differences after the intervention. We used an independent $t$-test to compare the differences between experimental and control groups. All statistical significance levels were set at $\alpha=0.05$. Within-group changes in VAS and grip strength were significantly different in both the experimental and control groups $(P<0.05)$. Between-groups after intervention, VAS and grip strength showed more improvement in the experimental group than in the control group $(P<0.05)$. This study showed that by applying CIT and taping to patients with $L E$, significant improvement in pain and grip strength could be obtained. Since the intervention had positive effects on LE by reducing pain and increasing grip strength, additional studies on efficient intervention will be conducted to develop exercise programs.

Keywords: Grip strength, Lateral epicondylitis, Proprioceptive neuromuscular facilitation, Taping, Visual analogue scale

\section{INTRODUCTION}

Lateral epicondylitis (LE) occurs in industry workers, housewives, and racket sports players who mainly perform repetitive movements of the wrist and forearm (Hong et al., 2004). The causes of LE are not fully understood, but some studies have implicated multiple ruptures of the extensor digitorum origin, calcification, degenerative changes of radial annular ligaments, and hypertrophy of synovial membranes. In addition, the extensor carpi radialis brevis and longus, extensor carpi ulnaris, and extensor digitorum have been reported to cause microruptures and inflammation of tendons connecting hypertrophied muscle to bone (Peters and Baker, 2001; Stasinopoulos and Johnson, 2007). Patients with LE have pain in the lateral epicondyle with flexion, wrist extension, and grip movements of the forearm. Acute anxiety and depression due to persistent pain cause difficulty in treatment. In addition, muscle power and endurance are reduced, and grip strength is reduced, leading to limitations in leisure activity and career activities in industrial settings. Patients with LE and repetitive and excessive use of the extensor carpi radialis and extensor carpi develop increased stiffness of soft tissues leading to pain (Kohia et al., 2008; Nagrale et al., 2009).

In a study of patients with LE to reduce stiffness of soft tissue, Ajimsha et al. (2012) showed that pain and functional disability levels were reduced by interfering with myofascial release (MFR). Segretin et al. (2016) showed significant differences in pain and

\footnotetext{
${ }^{*}$ Corresponding author: Jong-Eun Yim (iD https://orcid.org/0000-0001-7510-8233 Department of Physical Therapy, Sahmyook University, 815 Hwarang-ro,

Nowon-gu, Seoul 01795, Korea

E-mail: jeyim@syu.ac.kr

Received: February 15, 2019 / Accepted: March 26, 2019
}

This is an Open Access article distributed under the terms of the Creative Commons Attribution Non-Commercial License (http://creativecommons.org/licenses/by-nc/4.0/) which permits unrestricted non-commercial use, distribution, and reproduction in any medium, provided the original work is properly cited. 
grip strength as a result of intervention using eccentric exercise, stretching, and some daily self-exercises (transverse friction massage and stretching). Dilek et al. (2016) showed significant differences in pain, grip strength, and function as a result of intervention with elastic taping. In addition, Marcolino et al. (2016) showed significant differences in pain and functional changes as a result of stretching, deep tissue massage, and eccentric exercises.

Combined isotonic technique (CIT) for proprioceptive neuromuscular facilitation in this study used concentric, eccentric, and static contraction in muscle groups without relaxation (Kofotolis and Kellis, 2006). Eccentric contraction is especially effective in elongating soft tissue (Dean, 1988). Elastic and nonelastic taping was performed. The elastic tape is attached to a muscle group in the maximum elongation state, securing the space between the skin and the muscle to increase circulation of blood and lymph (Gerasimenko et al., 2015; Shim et al., 2003), and to improve motor function and promote normal physical activity (Costantino et al., 2016). Nonelastic tape was used to reduce pain (Shamsoddini and Hollisaz, 2013) by limiting joint movement and proprioceptive sensation by less active support structures such as ligaments and articular capsules (Briem et al., 2011).

A study to reduce pain and grip strength in patients with LE through relaxation of soft tissues is in progress, but no study has used CIT and few studies have used taping. The purpose of this study is to investigate the changes in pain and grip strength through intervention with CIT and taping in patients with LE and to develop an intervention method for LE.

\section{MATERIALS AND METHODS}

\section{Research design}

This study was a single-blind, randomized clinical trial that included 20 participants were randomly assigned to two groups: a experimental group (taping after CIT) and a control group (taping after stretching). Visual analogue scale (VAS) and grip strength were identified as the primary results. Concealed allocation was performed using a computer-generated randomized table of numbers created prior to data collection by an investigator. Before treatment and four weeks after treatment, an independent physical therapist who did not know the identity of each group assignment and patient's clinical information performed the evaluation. A separate form for evaluating the results was provided to the evaluator during the evaluation. Experimental and control groups intervention was applied by the same physical therapist, who was not involved in the outcome assessment. None of the participants received the previous taping (Fig. 1).

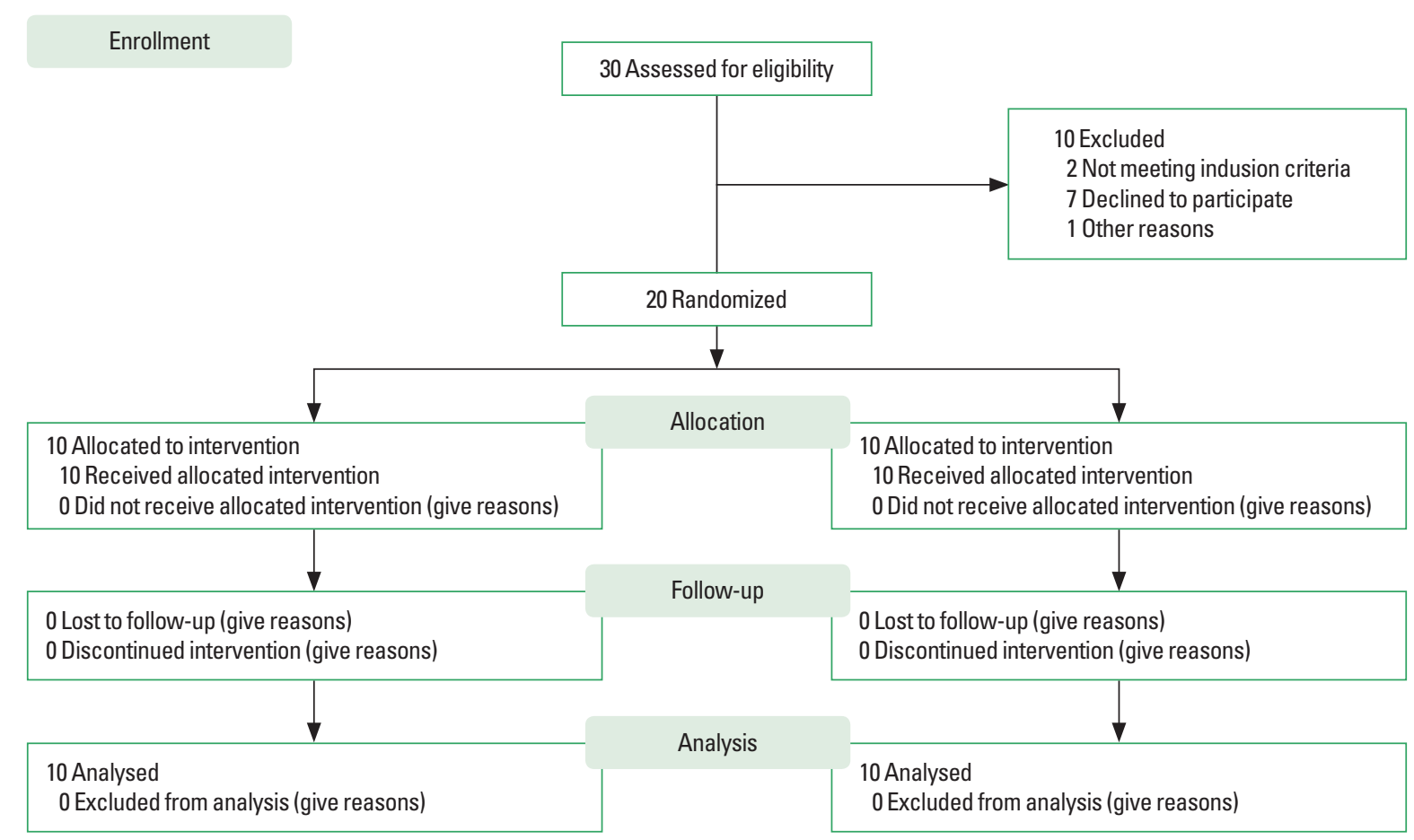

Fig. 1. Flow diagram of eligible patients in the current study. 


\section{Participants}

Pilot testing was performed on 6 volunteers ( 3 patients in the experimental group and 3 patients in the control group) to determine the number of participants required. Power analysis based on the results of the pilot study was completed to achieve a significant $\alpha$ level (0.05), power (0.80), and effect size (1.57). The results of the power analysis showed that the current study would require 8 participants in each group. G-Power software provided power analyses (G-Power software 3.1.2; Franz Faul, University of Kiel, Kiel, Germany).

This study was conducted at Design Hospital in Jeonju city between January and February 2019. Subjects were diagnosed with LE by an orthopedist, and a VAS score of 5 points or more was elicited for the lateral epicondyle with resistance applied on wrist extension. Twenty adult male and female subjects aged 30 to 45 years were included in the study. Participants with LE voluntarily agreed to participate in this study after hearing an explanation of the purpose and methods of this study. Patients were randomized to an experimental group $(n=10)$ with taping after CIT and a control group $(\mathrm{n}=10)$ with taping after stretching. The study was approved by the Institutional Review Board of the Sahmyook University (IRB No. 2-7001793-AB-N-012019014HR) in Seoul.

The inclusion criteria for participation were: (a) elbow pain for $>2$ months, (b) unilateral elbow pain, (c) pain with gripping, (d) pain with resisted wrist extension, (e) pain with passive wrist flexion with the elbow extension, and (f) tenderness on palpation over the lateral epicondyle of humerus. Patients who met certain criteria were excluded: (a) cardiovascular disease, (b) neurological disorders, (c) aversion to manual touch, (d) neuromuscular disease, (e) trauma to the previous elbow area, (f) elbow pain, (g) previous elbow surgery, (h) peripheral nerve entrapment, (i) cervical neuromuscular, (j) corticosteroid injections within 6 months, and (k) previous treatment of elbow joints. A summary of the clinical information of the participants can be found in Table 1 .

Table 1. General patient characteristics $(n=20)$

\begin{tabular}{lccc}
\hline Characteristic & $\begin{array}{c}\text { Experimental group } \\
(\mathrm{n}=10)\end{array}$ & $\begin{array}{c}\text { Control group } \\
(\mathrm{n}=10)\end{array}$ & P-value \\
\hline Sex, male:female & $6: 4$ & $6: 4$ & 1.00 \\
Age $(\mathrm{yr})$ & $37.90 \pm 4.53$ & $37.00 \pm 3.71$ & 0.64 \\
Height $(\mathrm{cm})$ & $168.10 \pm 8.08$ & $167.20 \pm 10.87$ & 0.17 \\
Weight $(\mathrm{kg})$ & $67.30 \pm 9.96$ & $67.70 \pm 9.72$ & 0.32 \\
Affected side, right:left & $9: 1$ & $8: 2$ & 1.00 \\
\hline
\end{tabular}

Values are presented as number or mean \pm standard deviation.

\section{Outcome measurements}

\section{Measurement of pain}

The measurement of pain was self-assessed using a VAS. Ten sections with a maximum pain score of 10 and a no pain score of 0 were marked on paper. Test-retest reliability was $r=0.96$ (Lingjaerde and Føreland, 1998).

\section{Measurement of grip strength}

We used a dynamometer (Jamar Hydraulic Hand Dynamometer, Sammons Preston Rolyan, Chicago, IL, USA) for the measurement of grip strength. Grip strength measurement was performed in wrist neutral position, with $90^{\circ}$ flexion of the elbow, and shoulder adduction with neutral rotation in sitting position to increase maximum muscle strength and objectivity (Balogun et al., 1991). Measurements were recorded as a mean value by testing a total of three times within the range of no pain.

\section{Intervention and procedure}

\section{Combined isotonic technique}

CIT was performed in a resting state with the affected side arm held comfortably on the treatment table. The subject began with the shoulder joint at $90^{\circ}$ flexion, upper arm neutral, elbow joint slightly flexed, forearm pronated, and wrist in neutral position (Pienimäki et al., 1996). The therapist performed CIT (concentric, eccentric, and static contraction) on the wrist extensor with the affected side wrist in flexion and ulnar deviation to a range without pain. CIT for the wrist consisted of a single application for 10 sec, with 10 repetitions, for a maximum of 5 min, with intervention performed 5 times a week for 4 weeks (Fig. 2).

\section{Stretching}

Stretching was performed in a resting state with the affected side arm held comfortably on the treatment table. The subject be-

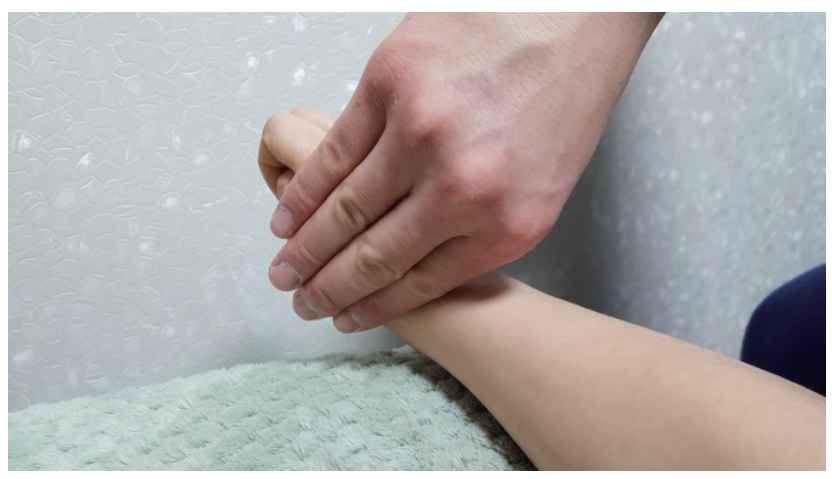

Fig. 2. Combined isotonic technique. 


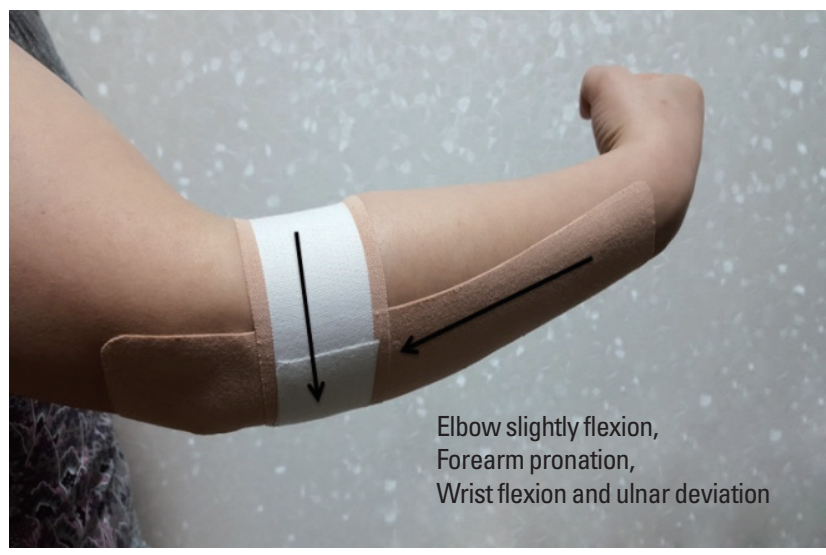

Fig. 3. Lateral epicondylitis taping.

gan with the shoulder joint at $90^{\circ}$ of flexion, with the upper arm neutral, elbow joint slightly flexed, forearm pronated, and wrist in neutral position (Pienimäki et al., 1996). The therapist performed stretching on the wrist extensor with the affected side wrist in flexion and ulnar deviation to a range without pain. The stretching for the wrist consisted of a single application $10 \mathrm{sec}$, with 10 repetitions, for a maximum of 5 min, with intervention performed 5 times a week for 4 weeks.

\section{Taping}

Although the diameter of the forearm region varies depending on the physical characteristics of a subject, about 30 to $35 \mathrm{~cm}$ of elastic tape (Benefact tape, Nippon Sigmax Co., Ltd., Tokyo, Japan) was used. With the elbow joint slightly flexed, forearm pronated, and wrist in neutral position, tape was attached to the extensor group through the lateral epicondyle in the wrist joint region in flexion and ulnar deviation to a painless range. Thereafter, the elastic tape was wound and fixed at the elbow in vertical direction to avoid interference with elbow joint flexion. Non-elastic tape (Battlewin C tape, NICHIBAN Co., Ltd., Tokyo, Japan) was again wound and fixed to the elastic tape (Fig. 3).

\section{Data analysis}

IBM SPSS ver. 18.0 (IBM Co., Armonk, NY, USA) was used for analysis. The general characteristics of subjects were normalized using the Shapiro-Wilk method. Paired $t$-tests were performed to examine the within-group changes in pain and grip strength after intervention with CIT and taping. Independent $t$-tests were conducted to compare the between-group difference between experimental and control groups. All statistical significance levels were set at $\alpha=0.05$.
Table 2. Visual analogue scale (VAS) scores pre- and postintervention

\begin{tabular}{lccccc}
\hline VAS score & $\begin{array}{c}\text { Experimental } \\
\text { group }(n=10)\end{array}$ & $\begin{array}{c}\text { Control group } \\
(n=10)\end{array}$ & $t$ & $P$-value ${ }^{\text {a) }}$ & $95 \% \mathrm{Cl}$ \\
\hline Preintervention & $5.62 \pm 0.66$ & $5.67 \pm 0.59$ & & & \\
Postintervention & $1.02 \pm 0.42$ & $3.31 \pm 0.62$ & -9.73 & 0.00 & -2.78 to -1.79 \\
$P_{\text {-value }}{ }^{\text {b) }}$ & 0.00 & 0.00 & & & \\
\hline
\end{tabular}

Values are presented as mean \pm standard deviation.

$\mathrm{Cl}$, confidence interval.

${ }^{\text {al }}$ Comparison between experimental and control group. ${ }^{\mathrm{b}}$ Comparison of VAS between pre- and postintervention under the same conditions.

Table 3. Grip strength pre- and postintervention

\begin{tabular}{lccccc}
\hline Grip strength & $\begin{array}{c}\text { Experimental } \\
\text { group }(n=10)\end{array}$ & $\begin{array}{c}\text { Control group } \\
(n=10)\end{array}$ & $t$ & $P$-value & $95 \% \mathrm{Cl}$ \\
\hline Preintervention & $26.20 \pm 7.83$ & $27.00 \pm 7.89$ & & & \\
Postintervention & $43.50 \pm 9.54$ & $35.60 \pm 6.83$ & 2.13 & 0.05 & 0.10 to 15.69 \\
$P_{\text {-value }}{ }^{\text {b) }}$ & 0.00 & 0.00 & & & \\
\hline
\end{tabular}

Values are presented as mean \pm standard deviation.

$\mathrm{Cl}$, confidence interval.

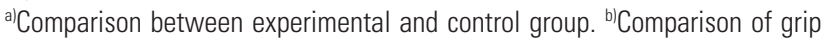
strength between pre- and postintervention under the same conditions.

\section{RESULTS}

\section{Comparison of VAS score changes}

Within-group changes in VAS scores showed significant differences between experimental $(t=19.52, P<0.05)$ and control groups $(t=9.17, P<0.05)$. The between-group changes in VAS scores after intervention showed significant differences between experimental and control groups $(t=-9.73 ; P<0.05 ; 95 \%$ confidence interval [CI], -2.78 to -1.79 ) (Table 2).

\section{Comparison of grip strength changes}

The within-group changes in grip strength showed significant differences between experimental $(t=-20.50, P<0.05)$ and control groups $(t=-14.80, P<0.05)$. The between-group changes in grip strength after intervention showed significant differences between experimental and control groups $(t=2.13 ; P<0.05 ; 95 \% \mathrm{CI}, 0.10$ 15.69) (Table 3).

\section{DISCUSSION}

This study aimed to determine the effects of CIT and taping on pain and grip strength in patients with LE. Patients with LE show a decrease in grip strength due to lateral epicondyle pain. Pain and grip strength seriously impair the ability to work and play racket sports (Binder and Hazleman, 1983). This study examined 
the effect of CIT and taping on lateral epicondyle pain and GS.

CIT combines concentric, eccentric, and static contraction without grip changes and rest, with a goal of an increase in power, endurance, coordination, and active control of motion (Kofotolis and Kellis, 2006). In particular, eccentric contraction displays force as the muscle elongates, and is effective in elongating soft tissues such as the fascia surrounding muscles, and tendons that connect muscle and periosteum (Dean, 1988). In a study by Peterson et al. (2014), 120 chronic LE patients were randomized into two groups of 60 to receive eccentric or concentric treatment. The eccentric group showed significant improvement in pain reduction and muscle strength. We conclude that intervention by combining two types of exercise will yield improved results. This supports the appropriateness of CIT in this study. Elongation of soft tissues shortens the healing process (Yi et al., 2018) and is considered to be an effective method for reducing pain and improving muscle strength.

Ajimsha et al. (2012) used MFR in 68 LE patients who were computer professionals. The result was a significant difference in pain reduction after 4 weeks, with persistence after 12 weeks. Yi et al. (2018) randomized 34 patients presenting with LE to a splinting and stretching group, a cortisone injection group, and a deep friction massage group for 2 weeks. There was significant pain reduction in the deep friction massage group compared to the splinting and stretching and the cortisone injection groups. The studies by Ajimsha et al. (2012) and Yi et al. (2018) included stretching through massage, and stretching caused tension stress on the myotendinous junction, increasing the length of the soft tissue (Appell, 1990). The CIT in this study included eccentric contraction, which can change the length of soft tissue, and two studies supported the appropriateness of CIT. Dilek et al. (2016) showed significant differences in pain reduction after taping for six weeks in 31 adult male and female subjects who had been diagnosed with LE. In this study, intervention with CIT and taping significantly decreased pain after intervention. There was also a significant between-group difference in experimental group with CIT and taping compared to that in the control group. The above results show that there is some difference according to the tape attachment method. The reason is that taping is relaxed in the wrist extensor group by attaching the tape to the wrist extensor in reverse action position; the pain is reduced by securing the soft tissue length through CIT.

Segretin et al. (2016) treated 23 subjects with LE using eccentric exercises (supinator and wrist extensor muscles), stretching, and some self-exercises (transverse friction massage and stretch- ing). There was a significant difference in grip strength after 3 months, which persisted after 6 months. Cho et al. (2018) conducted a double-blinded, randomized, cross-over study with 15 patients with chronic LE. Grip strength showed significant improvement in the taping group compared to that in the sham group. In this study, intervention with CIT and taping showed significant improvement after intervention. There was also a significant difference in the experimental group with CIT and taping compared to that in control group in a between-group comparison. These results indicate that the intervention with CIT and taping improves grip strength, and the intervention in this study also confirmed the effectiveness for grip strength.

Thus, CIT and taping intervention were found to be effective for pain reduction and grip strength increase. LE adversely affects workers and racket sports players. It is therefore an appropriate intervention method for subjects with weakened grip strength. CIT and taping are very cost-effective, with no side effects and a simple self-application procedure following repeated practice. Therefore, nonsurgical intervention for subjects with LE may be necessary. However, the small number of patients are important limitation to a final conclusion, but these issues are being solved by the study group, with an increase of the samples.

This study investigated the effects of CIT and taping on changes of pain and grip strength in patients with LE. The study showed significant improvement in pain reduction and grip strength increase. Thus, workers and racket sports players had very good pain reduction and grip strength increase. A future study will propose the development of an exercise program through study of efficient exercise interventions.

\section{CONFLICT OF INTEREST}

No potential conflict of interest relevant to this article was reported.

\section{ACKNOWLEDGMENTS}

This paper was supported by the Academic Research Fund of Dr. Myung Ki (MIKE) Hong in 2017.

\section{REFERENCES}

Ajimsha MS, Chithra S, Thulasyammal RP. Effectiveness of myofascial release in the management of lateral epicondylitis in computer professionals. Arch Phys Med Rehabil 2012;93:604-609. 
Appell HJ. Muscular atrophy following immobilisation. A review. Sports Med 1990;10:42-58.

Balogun JA, Akomolafe CT, Amusa LO. Grip strength: effects of testing posture and elbow position. Arch Phys Med Rehabil 1991;72:280-283.

Binder AI, Hazleman BL. Lateral humeral epicondylitis--a study of natural history and the effect of conservative therapy. Br J Rheumatol 1983;22:73-76.

Briem K, Eythörsdöttir H, Magnúsdóttir RG, Pálmarsson R, Rúnarsdöttir T, Sveinsson T. Effects of kinesio tape compared with nonelastic sports tape and the untaped ankle during a sudden inversion perturbation in male athletes. J Orthop Sports Phys Ther 2011;41:328-335.

Cho YT, Hsu WY, Lin LF, Lin YN. Kinesio taping reduces elbow pain during resisted wrist extension in patients with chronic lateral epicondylitis: a randomized, double-blinded, cross-over study. BMC Musculoskelet Disord 2018;19:193.

Costantino C, Pedrini MF, Licari O. Neuromuscular taping versus sham therapy on muscular strength and motor performance in multiple sclerosis patients. Disabil Rehabil 2016;38:277-281.

Dean E. Physiology and therapeutic implications of negative work. A review. Phys Ther 1988;68:233-237.

Dilek B, Batmaz I, Sarıyıldı MA, Sahin E, Ilter L, Gulbahar S, Cevik R, Nas K. Kinesio taping in patients with lateral epicondylitis. J Back Musculoskelet Rehabil 2016;29:853-858.

Gerasimenko MY, Knyazeva TA, V T, Kul'chitskaya DB. The application of the method of kinesio-taping technique for the combined non-pharmacological rehabilitation of the patients presenting with lymphedema of the lower extremities. Vopr Kurortol Fizioter Lech Fiz Kult 2015;92: 22-27.

Hong QN, Durand MJ, Loisel P. Treatment of lateral epicondylitis: where is the evidence? Joint Bone Spine 2004;71:369-373.

Kofotolis N, Kellis E. Effects of two 4-week proprioceptive neuromuscular facilitation programs on muscle endurance, flexibility, and functional performance in women with chronic low back pain. Phys Ther 2006;86:1001-1012.
Kohia M, Brackle J, Byrd K, Jennings A, Murray W, Wilfong E. Effectiveness of physical therapy treatments on lateral epicondylitis. J Sport Rehabil 2008;17:119-136.

Lingjaerde O, Føreland AR. Direct assessment of improvement in winter depression with a visual analogue scale: high reliability and validity. Psychiatry Res 1998;81:387-392.

Marcolino AM, das Neves LM, Oliveira BG, Alexandre AA, Corsatto G, Barbosa RI, de Cássia Registro Fonseca M. Multimodal approach to rehabilitation of the patients with lateral epicondylosis: a case series. Springerplus 2016;5:1718.

Nagrale AV, Herd CR, Ganvir S, Ramteke G. Cyriax physiotherapy versus phonophoresis with supervised exercise in subjects with lateral epicondylalgia: a randomized clinical trial. J Man Manip Ther 2009; 17:171-178.

Peters T, Baker CL Jr. Lateral epicondylitis. Clin Sports Med 2001;20:549563.

Peterson M, Butler S, Eriksson M, Svärdsudd K. A randomized controlled trial of eccentric vs. concentric graded exercise in chronic tennis elbow (lateral elbow tendinopathy). Clin Rehabil 2014;28:862-872.

Pienimäki TT, Tarvainen TK, Siira PT, Vanharanta H. Progressive strengthening and stretching exercises and ultrasound for chronic lateral epicondylitis. Physiotherapy 1996;82:522-530.

Segretin F, Paris G, Cheriet S, Delarue Y. Rehabilitation and auto-exercises protocol in patients with chronic lateral epicondylitis: 6 months follow-up. Ann Phys Rehabil Med 2016;59:e109.

Shamsoddini A, Hollisaz MT. Effects of taping on pain, grip strength and wrist extension force in patients with tennis elbow. Trauma Mon 2013; 18:71-74.

Shim JY, Lee HR, Lee DC. The use of elastic adhesive tape to promote lymphatic flow in the rabbit hind leg. Yonsei Med J 2003;44:1045-1052.

Stasinopoulos D, Johnson MI. It may be time to modify the Cyriax treatment of lateral epicondylitis. J Bodyw Mov Ther 2007;11:64-67.

Yi R, Bratchenko WW, Tan V. Deep friction massage versus steroid injection in the treatment of lateral epicondylitis. Hand (N Y) 2018;13:56-59. 